\section{Grit and grain}

Robert S. Anderson

Aeolian Sand and Sand Dunes. By Kenneth Pye and Haim Tsoar. Hyman: 1990. Pp.396. $£ 70$.

THE world has recently witnessed a war fought along and above the sandy desert surfaces of Iraq and Kuwait, a war waged, ultimately, for control over vast oil reserves trapped at depth in porous sandstone and carbonate reservoirs. Throughout the world, people produce crops grown in a granular substrate that has a nasty habit of being blown away by the wind, and whose success or failure depends upon the vicissitudes of climate. Although deep-sea deposits com-

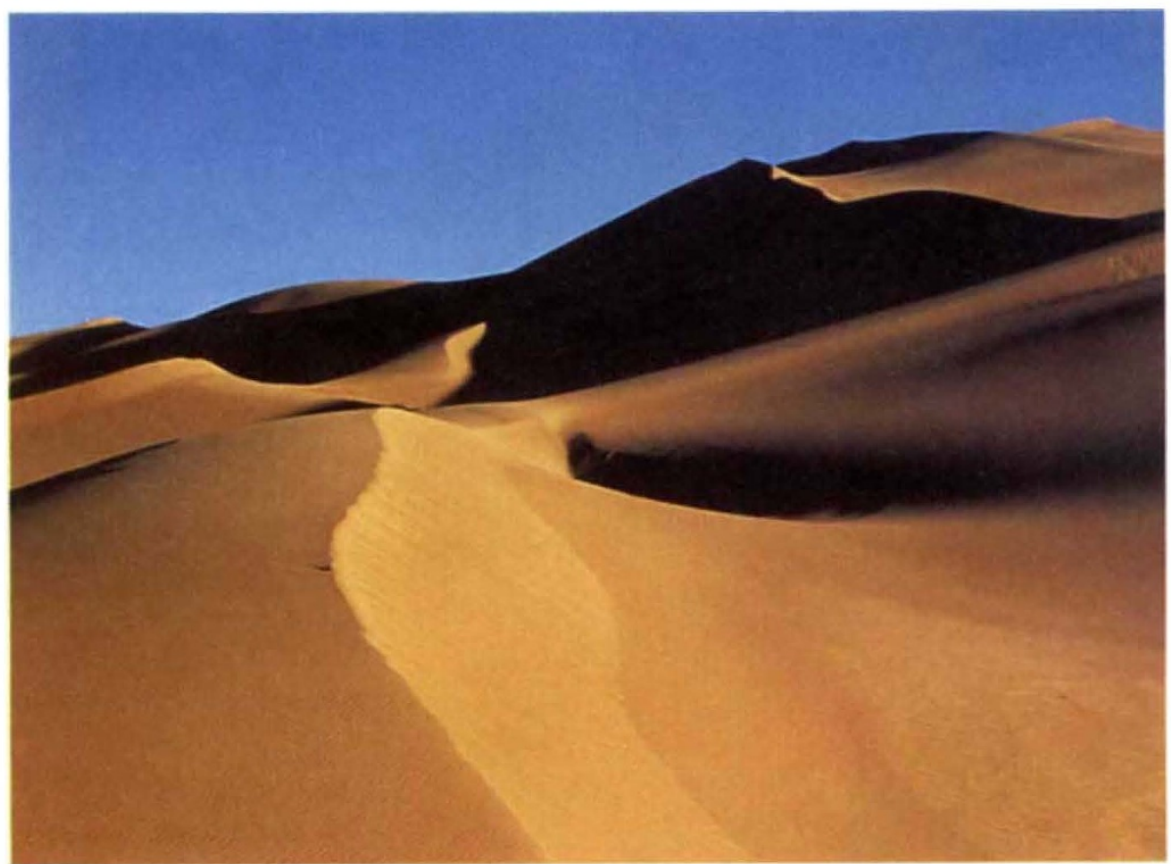

Shifting sands - human interaction with a sandy substrate goes back to the Middle Ages.

prise the principal source of our climate record, the distribution of aeolian (windblown) deposits provides an important component of the terrestrial record, from which one wishes to infer the histories of wind speeds, directions and vegetational resistance to sand transport. It is therefore of increasing interest to understand the processes involved in the transport, deposition and lithification of sand, and to amass case histories of climate from such deposits.

Kenneth Pye and Haim Tsoar, both with extensive experience in aeolian matters, have teamed up to produce Aeolian Sand and Sand Dunes, a book whose primary purpose is to collect the disparate and growing literature on the topic. The book may be viewed as a sequel to Pye's first book, Aeolian Dust and Dust Deposits(Academic, 1987). Both serve as large-scale literature reviews, introducing the reader to recent work on the nature of the materials, the conditions under which these grains will be transported, the mechanics of the transport process, the deposits they engender, the postdepositional modification of the sediments, and the history of climate one may infer from a study of the deposits.

This is the second of two recent attempts to collect together the aeolian literature. The first, R. Greeley and J. Iversen's Wind as a Geological Process (Cambridge University to provide a context in which to interpret wind transport systems on other planets. Pye and Tsoar emphasize instead the sedimentological techniques and problems, and on these fronts they largely succeed. We learn about the history of the coastal dunefield of Oregon, about the Simpson-Strzelecki sand sea of central Australia, and about the postdepositional cementation processes. Also discussed is the evidence used to infer that Press, 1985), sought to review the literature also parochial in the sense that they have not incorporated extensive developments in our understanding of aqueous sediment transport over the past 20 years that are indeed pertinent to an understanding of aeolian sediment transport and associated bedforms. In their defence, however, this is also one of the faster-growing portions of the literature. The physics community has recently become engaged by treating both the saltation transport up the windward sides of dunes and the grain flows down the lee sides of sand dunes as examples of a general class of problems in granular mechanics. The most recent work will appear soon in two special issues of $A$ cta Mechanica.

Robert S. Anderson is in the Department of Earth Sciences, University of California, Santa Cruz, California 95064, USA.

\section{The bangs of a magician's brain}

Alvaro De Rújula

The Charm of Physics. By Sheldon L. Glashow. American Institute of Physics: 1991. Pp.300. \$27.95, £17.50.

GrEAT steps in our knowledge of physical reality often occur in the form of a 'unification': an understanding of different concepts or phenomena as aspects of the same underlying principles. No doubt the greatest unification of all times is that due to Newton: the discovery that the motions of the Moon, the planets and the fake proverbial apple all obey the same universal law. Competing for second place are Maxwell, for the unification of electricity, magnetism and light, and Einstein, for unifying light (or gravity), space and time. No doubt the Swedish Academy would vote for Maxwell, as Einstein was never awarded the Nobel prize for either of his 'relativities'.

Sheldon L. Glashow, Abdus Salam and Steve Weinberg received the 1979 Nobel prize for the most recent unification, that of electromagnetism and the weak interactions. Perhaps in an attempt to compensate for its earlier disregard of unifications, the Swedish Academy awarded this particular prize before experiment had confirmed the main prediction of the new theory by proving the existence of the $\mathrm{W}$ and $\mathrm{Z}$ particles that are the 'carriers' of the weak force. The daring Swedes must have held their breath rather tightly for the few years that elapsed until the actual discovery of these particles.

The Charm of Physics is a collection of essays by Sheldon Glashow, many of them appearing in print for the first time. The essays date from 1975 to the present, and have not been edited to exploit the benefit of hindsight. Sometimes they relate to a very particular occasion, and the book is best read with this in mind. For example, the first 